\title{
Presence of glucose, xylose, and glycerol fermenting bacteria in the deep biosphere of the former Homestake gold mine, South Dakota
}

\section{Gurdeep Rastogi ${ }^{1+}$, Raghu N. Gurram ${ }^{1}$, Aditya Bhalla ${ }^{1}$, Ramon Gonzalez ${ }^{2}$, Kenneth M. Bischoff ${ }^{3}$, Stephen R. Hughes ${ }^{3}$, Sudhir Kumar ${ }^{1}$ and Rajesh K. Sani ${ }^{1 *}$}

\author{
' Department of Chemical and Biological Engineering, South Dakota School of Mines and Technology, Rapid City, SD, USA \\ ${ }^{2}$ Departments of Chemical and Biomolecular Engineering and Bioengineering, Rice University, Houston, TX, USA \\ ${ }^{3}$ Renewable Product Technology Research Unit, Agricultural Research Service, National Center for Agricultural Utilization Research, US Department of Agriculture, \\ Peoria, IL, USA
}

Edited by:

Eric Altermann, AgResearch Ltd.,

New Zealand

\section{Reviewed by:}

Carl J. Yeoman, Montana State

University, USA

Romy Chakraborty, Lawrence

Berkeley National Lab, USA

\section{*Correspondence:}

Rajesh K. Sani, Department

of Chemical and Biological

Engineering, South Dakota School

of Mines and Technology,

501 East St. Joseph Street

Rapid City, SD 57701, USA.

e-mail: rajesh.sani@sdsmt.edu

${ }^{\dagger}$ Present address:

Gurdeep Rastogi, Chilika

Development Authority, Forest and

Environment Department,

Government of Odisha, India.
Eight fermentative bacterial strains were isolated from mixed enrichment cultures of a composite soil sample collected at $1.34 \mathrm{~km}$ depth from the former Homestake gold mine in Lead, SD, USA. Phylogenetic analysis of their 16S rRNA gene sequences revealed that these isolates were affiliated with the phylum Firmicutes belonging to genera Bacillus and Clostridium. Batch fermentation studies demonstrated that isolates had the ability to ferment glucose, xylose, or glycerol to industrially valuable products such as ethanol and 1,3-propanediol (PDO). Ethanol was detected as the major fermentation end product in glucose-fermenting cultures at $\mathrm{pH} 10$ with yields of $0.205-0.304 \mathrm{~g}$ of ethanol $/ \mathrm{g}$ of glucose. While a xylose-fermenting strain yielded $0.189 \mathrm{~g}$ of ethanol $/ \mathrm{g}$ of xylose and $0.585 \mathrm{~g}$ of acetic acid $/ \mathrm{g}$ of xylose at the end of fermentation. At pH 7, glycerol-fermenting isolates produced PDO (0.323-0.458 g of PDO $/ \mathrm{g}$ of glycerol) and ethanol $(0.284-0.350 \mathrm{~g}$ of ethanol/g of glycerol) as major end products while acetic acid and succinic acid were identified as minor by-products in fermentation broths. These results suggest that the deep biosphere of the former Homestake gold mine harbors bacterial strains which could be used in bio-based production of ethanol and PDO.

Keywords: bioenergy, bioethanol, biofuels, fermentation, gold mine, 1,3-propanediol

\section{INTRODUCTION}

Lignocellulosic biomass represents an inexpensive, abundant, and renewable biological resource that has great potential for the production of biofuels (Himmel et al., 2007). Many factors, such as the highly resistant nature of lignin and the crystallinity of cellulose along with structural complexity make lignocellulose recalcitrant toward biological and chemical degradation (Zheng et al., 2009). Alkaline pretreatment breaks lignin-carbohydrate bonds in lignocellulosic biomass and has been used extensively to increase the enzymatic digestibility of switchgrass and prairie cordgrass, which are promising biomass feedstocks especially in South Dakota (Gonzalez-Hernandez et al., 2009; Karunanithy and Muthukumarappan, 2011). However, the major problem associated with alkali pretreatment is that it raises the $\mathrm{pH}$ of medium containing biomass to the highly alkaline $(>10)$ range, which is not optimal for fermenting microorganisms such as Saccharomyces cerevisiae and Zymomonas mobilis that perform fermentation only under acidic $\mathrm{pH}$ (5.0) conditions (Zaldivar et al., 2001; Zheng et al., 2009). At industrial scale of biomass fermentation, large $\mathrm{pH}$ shifts (highly alkaline) require significant use of acids, resulting in an increased amount of waste salt products that must be disposed of appropriately. Furthermore, $S$. cerevisiae and $Z$. mobilis are of limited use in fermentation of biomass with high pentose content, as they cannot ferment pentose sugars unless they are genetically engineered to express the desired pathways (Zaldivar et al., 2001). Although, ethanol producing strains of Escherichia coli can degrade pentose and hexose sugars, the fermentation reactions are generally carried out at $\mathrm{pH}$ 7. Therefore, E. coli is also not suitable for fermentation of alkali-treated biomass (Zaldivar et al., 2001). From this perspective, novel bacteria with different spectra of abilities, such as those that can ferment glucose and xylose sugars under alkaline conditions, will lead to a cost-effective and environmentally friendly bioethanol production process.

Another problem associated with bioconversion of feedstocks such as soybean, vegetable, canola, and waste oils and animal fats into biofuels is the generation of glycerol as a major byproduct (Yazdani and González, 2007; Yazdani et al., 2010). For example, it has been shown that for every $100 \mathrm{~kg}$ of biodiesel or bioethanol produced, the amounts of crude glycerol produced are 4 and $10 \mathrm{~kg}$, respectively (Barbirato et al., 1998; Maervoet et al., 2011). With increased emphasis placed on bioethanol and biodiesel production, there is also an increase in the amount of crude glycerol produced. In Europe, the amount of waste glycerol produced was more than 700 kilotons in year 2008. In the US, the amount of crude glycerol produced has reached approximately 251 kilotons per year (Valdivieso, 2010). Crude glycerol contains several impurities (alcohol, salts, and heavy metals) and 
for small-scale biofuels industries, purification of this crude glycerol is not economical. As more and more crude glycerol is produced from the biofuel industries, methods to use this waste product effectively will be advantageous to further minimize the cost of production of biofuels. One such method is microbial transformation of waste glycerol to valuable products such as 1,3-propanediol (PDO) which offers a promising alternative to manage waste glycerol.

PDO is a very valuable chemical that is used in the synthesis of various polyesters, polyurethane, lubricant, solvent, and as a precursor in the chemical and pharmaceutical industries (Saxena et al., 2009; Maervoet et al., 2011). Although conventional chemical methods do exist for the synthesis of PDO, the process is quite expensive due to use of high pressure, temperature, and expensive catalysts along with generation of toxic intermediates. Thus, anaerobic microbial conversion of crude glycerol to produce PDO is an area of extensive research and provides a way to capitalize on the surplus of waste glycerol (Thompson and He, 2006). However, so far only a few bacterial species belonging to genera Clostridium, Klebsiella, Enterobacter, Lactobacillus, Citrobacter, and Bacillus have been shown to convert glycerol into PDO under anaerobic conditions (Zhao et al., 2006; Willke and Vorlop, 2008; da Silva et al., 2009; Saxena et al., 2009). Considering the rapidly growing market for PDO and to deal with the problem of waste glycerol, there is increasing need to isolate and characterize new strains of bacteria that can ferment glycerol into PDO.

It is apparent that there are several constraints associated with biofuels production such as limited availability of bacterial strains that can ferment alkali-treated biomass or ferment glycerol to commodity chemicals (e.g., ethanol, PDO). Considering these limitations, we have isolated glucose-, xylose-, or glycerol-fermenting bacteria from the extreme deep biosphere environment of the former Homestake gold mine, Lead, SD. There are very few reports on subsurface isolates utilizing glucose for ethanol production (Alain et al., 2002; Slobodkin et al., 2003; Slobodkina et al., 2008) but the information on xylose and glycerol fermenting deep subsurface microbes is relatively scarce. Deep subsurface microbes, Tepidibacter thalassicus and Clostridium tepidiprofundi sp. nov., fermented glucose into ethanol, acetate, and $\mathrm{H}_{2}$ (Slobodkin et al., 2003; Slobodkina et al., 2008). Another strain, Caminicella sporogenes gen. nov., sp. nov., produced $\mathrm{H}_{2}$, acetate, butyric acid and ethanol when grown on glucose as a substrate (Alain et al., 2002). In this study we characterized the biotechnological potential of seven strains for ethanol and PDO production using laboratory batch fermentation studies.

\section{MATERIALS AND METHODS \\ SITE DESCRIPTION AND SOIL COLLECTION}

The Homestake mine $\left(44^{\circ} 35^{\prime} 2074^{\prime \prime} \mathrm{N}, 103^{\circ} 75^{\prime} 082^{\prime \prime} \mathrm{W}\right.$; Lead, SD) is the deepest mine $(2.4 \mathrm{~km}$ deep) in North America and had the largest gold deposits ever found in the Western Hemisphere (Rastogi et al., 2009b). This former gold mine is now known as Sanford Underground Research Facility (SURF). A detailed description of the mine is located at http://www.dusel.org/. In May 2008, a composite soil sample was collected at a depth of $1.34 \mathrm{~km}$ from the Ross shaft as described earlier (Rastogi et al., 2010a,b). A schematic cross section, location of sampling site, and elemental composition of the soil samples used in the present study have been described elsewhere (Rastogi et al., 2009b).

\section{ENRICHMENT AND ISOLATION OF GLUCOSE-, XYLOSE-, AND GLYCEROL-FERMENTING BACTERIA}

The glucose and xylose fermentation medium contained (per liter): $0.1 \mathrm{~g}$ nitriloacetic acid, $1 \mathrm{ml} \mathrm{FeCl} 3$ solution (0.03\%), $0.05 \mathrm{~g}$ $\mathrm{CaCl}_{2} \cdot 2 \mathrm{H}_{2} \mathrm{O}, 0.1 \mathrm{~g} \mathrm{MgSO}_{4} \cdot 7 \mathrm{H}_{2} \mathrm{O}, 0.005 \mathrm{~g}$ methionine, $1.8 \mathrm{~g}$ of $85 \% \mathrm{H}_{3} \mathrm{PO}_{4}, 0.05 \mathrm{~g}$ yeast extract, $0.01 \mathrm{~g}$ casamino acids, $0.01 \mathrm{~g}$ $\mathrm{KCl}, 0.3 \mathrm{~g} \mathrm{NH}_{4} \mathrm{Cl}$, and $1 \mathrm{ml}$ of Nitsch's trace element solution (Rastogi et al., 2009a). The $\mathrm{pH}$ of the medium was adjusted to 10 using $10 \mathrm{M} \mathrm{NaOH} /$ glycine mixture to specifically enrich alkaliphilic fermentative bacteria. After autoclaving, the medium was supplemented with filter-sterilized solutions of D-xylose or D-glucose as a source of carbon to achieve a final concentration of $5 \mathrm{~g} / \mathrm{L}$ of these sugars. For enrichment and isolation of glycerol-fermenting bacteria, the medium contained the following components (per liter): $7 \mathrm{~g} \mathrm{~K}_{2} \mathrm{HPO}_{4}, 2 \mathrm{~g} \mathrm{KH}_{2} \mathrm{PO}_{4}, 2 \mathrm{~g} \mathrm{NH} 4 \mathrm{Cl}$, $2 \mathrm{~g} \mathrm{MgSO}_{4} .7 \mathrm{H}_{2} \mathrm{O}, 0.5 \mathrm{~g} \mathrm{NaCl}, 6.61 \mathrm{~g}\left(\mathrm{NH}_{4}\right)_{2} \mathrm{SO}_{4}, 40 \mathrm{~g}$ glycerol, and $1 \mathrm{~g}$ yeast extract, and the $\mathrm{pH}$ of the medium was adjusted to 7. The glycerol fermentation medium was derived from the study of Zheng et al. (2008).

One gram of soil sample was aseptically added to $125-\mathrm{ml}$ serum bottles containing $100 \mathrm{ml}$ of pre-sterilized xylose, glucose, or glycerol fermentation medium. The serum bottles were sealed with butyl rubber stoppers, crimped with aluminum seals, and sparged with ultra-pure $\mathrm{N}_{2(\mathrm{~g})}$ for $15 \mathrm{~min}$ to remove the dissolved and head space oxygen for creating anaerobic conditions (Sani et al., 2010). All enrichments were performed by incubating the serum bottles at $37^{\circ} \mathrm{C}$ in an incubator shaker (120 rpm) for 2-4 days. Triplicate serum bottles were used for each enrichment experiment, and controls included were: (1) soil samples autoclaved at $121^{\circ} \mathrm{C},(2)$ soil-free controls, and (3) carbon source-free controls. Growth of enrichment cultures was monitored periodically by measuring total cell protein using a quantitative colorimetric Coomassie assay (Sani et al., 2001) and cultures showing growth were transferred into fresh fermentation medium. This process was repeated five times prior to initiating the isolation of pure cultures by deep agar plate technique from mixed enrichments. In brief, $100 \mu$ l of fifth-generation mixed enrichment cultures was added to $100 \mathrm{ml}$ of sterile and lukewarm xylose, glucose, or glycerol agar medium, mixed well and poured immediately into petri plates. Triplicate agar plates from each enrichment culture were incubated under anaerobic conditions in $\mathrm{BBL}^{\circledR}$ Gas-Pak ${ }^{\circledR}$ containers (Becton Dickinson) for $2-4$ days in the dark at $37^{\circ} \mathrm{C}$. After incubation well-separated colonies that were embedded into agar were picked and inoculated into serum bottles containing fresh medium having a particular carbon source (glucose, xylose, or glycerol).

\section{S rRNA GENE SEQUENCE ANALYSIS OF GLUCOSE-, XYLOSE-, AND GLYCEROL-FERMENTING BACTERIA}

Total DNA was extracted from $10 \mathrm{ml}$ of pure cultures of glucose-, xylose-, and glycerol-fermenting isolates. PCR amplification of nearly full-length $16 \mathrm{~S}$ rRNA genes from each isolate was carried out using the primer set 8f/1492r and amplification conditions as 
described earlier (Rastogi et al., 2009a). Sequencing of 16S rRNA genes was performed commercially, and similarity searches for sequences were performed by BLAST $(N)$. Sequences were aligned using the CLUSTALW, and phylogenetic trees were constructed using the neighbor-joining method (1000, bootstrap replicates) by MEGA v 3.1 (Kumar et al., 1993). All 16S rRNA sequences generated in this study have been deposited in GenBank under accession numbers GQ254068-GQ254079.

\section{MEASUREMENT OF TOTAL CELL PROTEIN, METABOLITES, AND SUBSTRATE CONSUMPTION}

The isolates were grown anaerobically in serum bottles containing $100 \mathrm{ml}$ liquid medium with a particular carbon source xylose, glucose or glycerol. After the exponential phase of growth, the cells from seed cultures were re-inoculated into serum bottles containing $100 \mathrm{ml}$ medium with the same carbon source, and anaerobic conditions were created. The inoculated bottles were incubated at $37^{\circ} \mathrm{C}$ under shaking conditions ( $120 \mathrm{rpm}$ ) for 6 days. Samples were withdrawn periodically and analyzed for soluble intermediates and end products. Samples were prepared for highpressure liquid chromatography (HPLC) by centrifuging 1-ml cultures at $10,000 \mathrm{rpm}$, and the resulting supernatant was further filtered using $0.2 \mu \mathrm{m}$ pore size membrane filters (Gelman Acrodisc). HPLC employed a $300 \mathrm{~mm}$ Aminex HPX 87H column (Bio-Rad Laboratories, Inc., Hercules, CA) on a HP 1100 Series HPLC system equipped with a refractive index detector (Agilent Technologies, Santa Clara, CA). Samples $(10 \mu \mathrm{l})$ were injected onto a heated column $\left(65^{\circ} \mathrm{C}\right)$ and eluted at $0.6 \mathrm{ml} / \mathrm{min}$ using $5 \mathrm{mM} \mathrm{H}_{2} \mathrm{SO}_{4}$ as mobile phase. The identification of fermentation product PDO was confirmed using HPLC and 1D proton nuclear magnetic resonance as described earlier (Dharmadi and Gonzalez, 2005; Murarka et al., 2008). All experiments were performed in duplicate and control serum bottles with no carbon source were also included.

\section{DETERMINATION OF SPECIFIC GROWTH RATES AND YIELD COEFFICIENTS}

Bacterial growth rate is a time-dependent variable in cultures. In each sample discrete growth rate measurements were calculated for each time step. Equation 1 was used to obtain each discrete growth rate datum point as described earlier (Chhatwal, 2008).

$$
\mu_{i}=\left(\frac{1}{t}\right) \ln \left(\frac{X_{i}}{X_{0}}\right)
$$

In Equation 1 " $\mu_{i}$ ” represents the calculated growth rate (in $\mathrm{hr}^{-1}$ ) and " $X_{i}$ " is the measured cell mass concentration $(\mathrm{g} / \mathrm{L})$. The " $i$ " subscript is a counter variable for each time step. Similarly, " $X_{0}$ " represents cell concentration at time $t=0$. The variable " $t$ " is time (hour). The arithmetic mean of data obtained was then calculated and represented as specific growth rate, " $\mu$ ".

Yield coefficients ( $\mathrm{g}$ of biomass $[\mathrm{X}]$ or product $[\mathrm{P}]$ formed per $\mathrm{g}$ of substrate [S] consumed) were defined based on the amount of consumption of xylose, glucose, or glycerol. Growth yields were calculated from Equation 2.

$$
Y_{X / S} \equiv-\frac{\Delta X}{\Delta S}
$$

Product yields on substrate were calculated from Equation 3.

$$
Y_{P / S}=-\frac{\Delta P}{\Delta S}
$$

\section{RESULTS AND DISCUSSION MOLECULAR IDENTIFICATION OF GLUCOSE-, XYLOSE-, AND GLYCEROL-FERMENTING BACTERIA}

A total of eight bacterial strains were purified from three different enrichment cultures and were used to ferment glucose, xylose, or glycerol. Figure 1 shows the phylogenetic identification of these isolates and the type of enrichment culture from which they have been purified. All isolates were found affiliated with phylum Firmicutes and grouped within the Clostridiaceae and Bacillaceae families. A majority of isolates (7 out of 8) were closely related to Clostridium sp. except a single isolate (DUSELGlu2) that closely grouped with sequences from Bacillus sp. These findings were in agreement with earlier studies from the Homestake mine, where Clostridium sp. has been shown to be the most predominant member (up to $62.3 \%$ ) followed by Bacillus sp. (32.7\%) in cellulose-degrading enrichment cultures (Rastogi et al., 2009a). Clostridium spp. have been shown to ferment glucose, xylose, or glycerol to produce various alcohols (e.g., ethanol, butanol), acids (e.g., lactic, acetic, butyric acids), and PDO (Balasubramanian et al., 2001; Ni and Sun, 2009; Jiang et al., 2010; Maervoet et al., 2011). Although several Bacillus species have been reported to produce ethanol (Romero et al., 2007; Ou et al., 2009), none of them has been shown to ferment glucose into ethanol especially under alkaline $\mathrm{pH}$ conditions as observed in the case of the DUSELGlu2 strain that belonged to genus Bacillus based on $16 \mathrm{~S}$ rRNA phylogenetic analysis (Figure 1).

\section{BATCH FERMENTATION OF XYLOSE BY DEEP-MINE ISOLATE}

Xylose fermentation by DUSELXyl3 strain was studied in anaerobic batch cultures. After a lag of 6 h, DUSELXyl3 strain started utilizing xylose as carbon source, which was evident by a net increase in total cell protein and a decrease in xylose concentration in fermentation broth (Figure 2A). During the exponential growth phase, xylose fermentation produced acetic acid that decreased the $\mathrm{pH}$ of fermentation broth from 10 to 4.5 (Figure 2A). It is possible that low $\mathrm{pH}$ conditions generated in the fermentation broth might have affected metabolic pathways involved in xylose utilization and probably inhibited them. This was in line with batch fermentation profile of DUSELXyl3 strain which revealed this strain fermented only about $43 \%$ of the initial xylose concentration during $150 \mathrm{~h}$ of incubation (Figure 2A). HPLC analysis revealed that DUSELXyl3 produced acetic acid $(1.56 \mathrm{~g} / \mathrm{L}$, data not shown) as a primary metabolite rather than ethanol $(0.52 \mathrm{~g} / \mathrm{L})$ at the end of fermentation. DUSELXyl3 produced $0.189 \mathrm{~g}$ of ethanol/g of xylose which was about $37 \%$ of theoretical yield for complete conversion of sugar to ethanol.

\section{BATCH FERMENTATION OF GLUCOSE BY DEEP-MINE ISOLATES}

Glucose-fermenting strains DUSELGlu1, DUSELGlu2, and DUSELGlu4 demonstrated similar batch fermentation profiles with respect to product formation, substrate consumption, and $\mathrm{pH}$ shifts in fermentation broth. For example, within $40 \mathrm{~h}$ of fermentation, DUSELGlu4 completely utilized the glucose that 


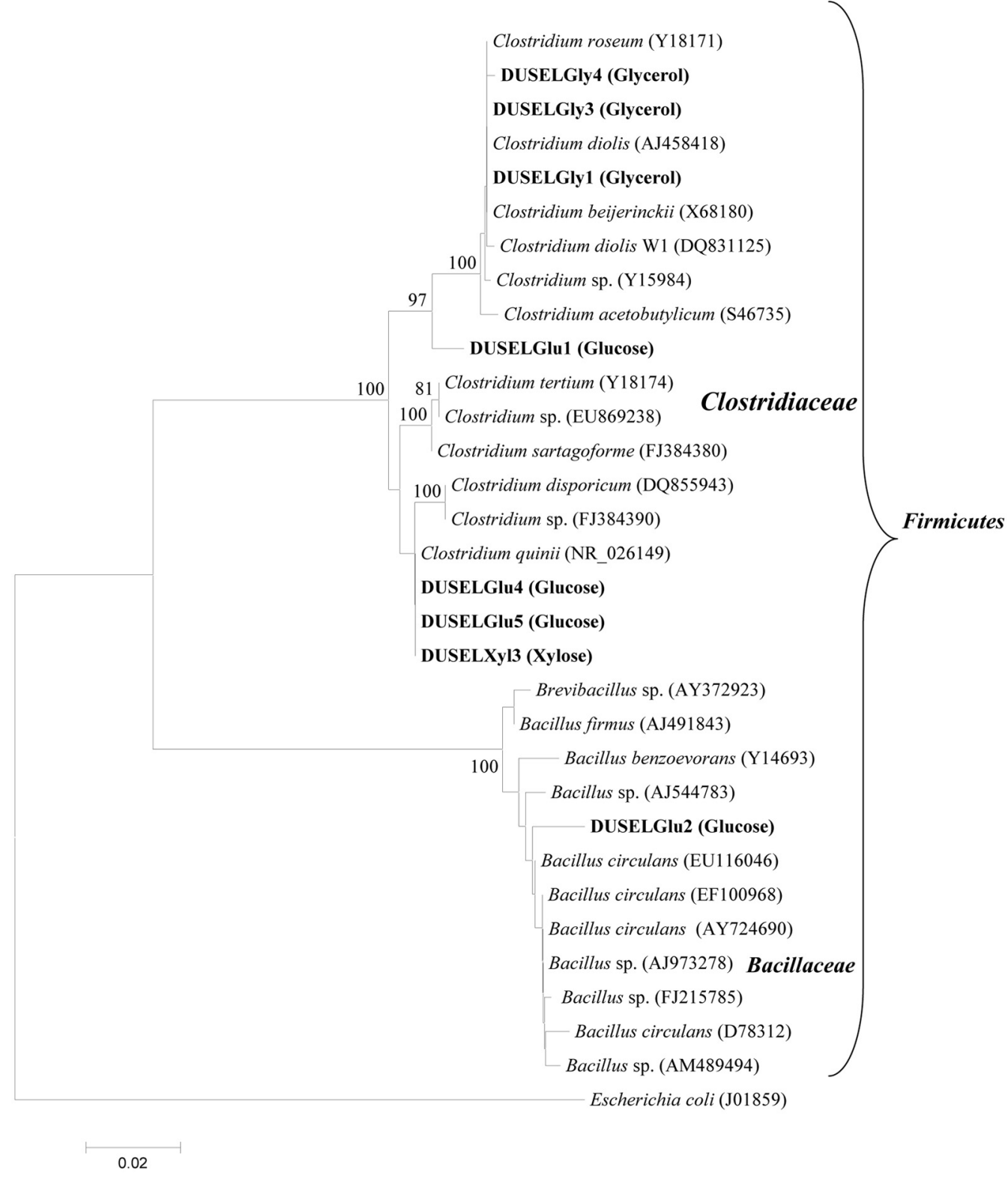

FIGURE 1 | Phylogenetic tree showing the relationship of 16S rRNA gene sequences retrieved from xylose-, glucose-, or glycerol-fermenting DUSEL strains with reference sequences of Clostridium and Bacillus sp. obtained from GenBank. The type of enrichment medium from which a particular strain was isolated has been indicated in parenthesis along with the strain name in bold. E. coli (J01859) was selected as out-group to root the tree. The scale bar represents 0.02 substitutions per nucleotide position. Bootstrap values which were $<75 \%$ are not shown. was available in the broth indicating that glucose can be readily fermented into ethanol in a short span of time. In all three glucose-fermenting strains, ethanol (0.205-0.304 g ethanol/g glucose) was detected as the primary product at the end of fermentation with small amounts of acetic acid (0.593-0.742 g/l, data not shown), and lactic acid $(0.013-0.45 \mathrm{~g} / \mathrm{L}$, data not shown). Interestingly, the concentration of lactic acid dropped below the limit of detection at the end of fermentation in DUSELGlu1 and DUSELGlu4 strains, while in DUSELGlu2 strain, it turned out to be the third fermentation product along with ethanol and acetic acid. All three glucose-fermenting isolates showed similar ethanol yields and specific growth rates (Tables 1 and 2). Based on a theoretical maximum yield of $0.51 \mathrm{~g}$ ethanol/g sugars (Krishnan et al., 1999), the yield of ethanol in DUSELGlu2 strain was $0.304 \mathrm{~g}$ of ethanol/g of glucose which was $60 \%$ of theoretical maximum yield.

The specific growth and metabolite product profiles of both xylose- and glucose-fermenting deep-mine strains showed that ethanol was not a growth-associated metabolite as it was formed after the exponential phase of growth (Figures 2A and B for 


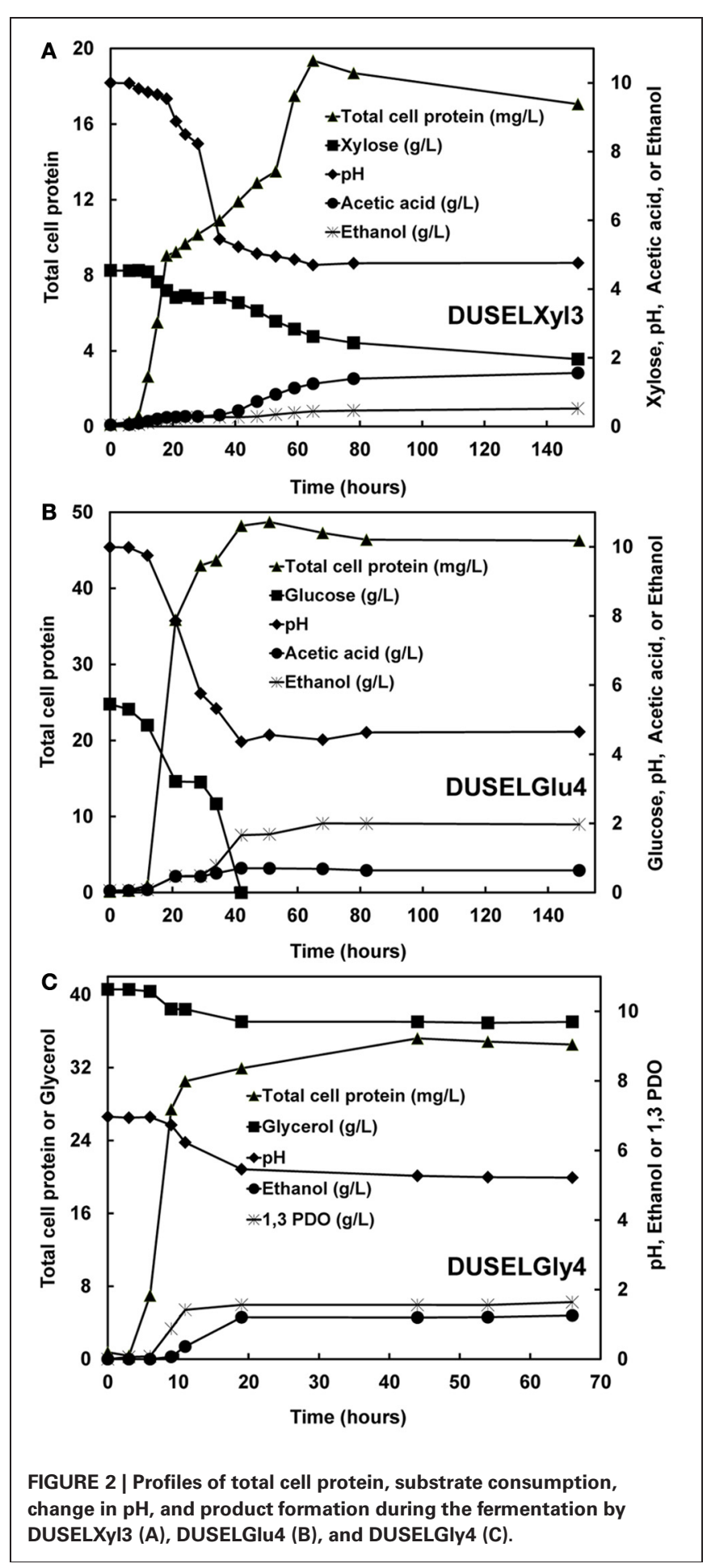

DUSELXyl3 and DUSELGlu4, respectively). In previous studies, strains of E. coli, Klebsiella oxytoca, and Zymomonas mobilis have been shown to produce very high amounts $(23-63 \mathrm{~g} / \mathrm{L})$ of ethanol from xylose and glucose fermentations (Yomano et al., 1998; Dien et al., 2003). Noticeably, these studies have used mutant/recombinant strains over-expressing a desired metabolic pathway, specialized growth media, sugar mixtures, and inoculation protocols. Our data on the fermentation of glucose, xylose, and glycerol by deep-mine isolates were generated under un-optimized minimal medium and culture conditions using wild-type strains. Therefore, detailed comparisons of deepmine strains with earlier reports were not possible. Nonetheless, recombinant $E$. coli strains have been shown to produce $0.5 \mathrm{~g}$ ethanol/g of glucose in LB medium (de Carvalho Lima et al., 2002). Noticeably, our wild-type DUSELGlu2 strain produced $0.304 \mathrm{~g}$ ethanol $/ \mathrm{g}$ of glucose in a minimal fermentation medium (Table 2). Furthermore, metabolically engineered $S$. cerevisiae strains have been shown to produce $0.35-0.38 \mathrm{~g}$ ethanol $/ \mathrm{g}$ of xylose (Eliasson et al., 2000).

\section{BATCH FERMENTATION OF GLYCEROL BY DEEP-MINE ISOLATES}

All three glycerol-fermenting isolates, DUSELGly1, DUSELGly3, and DUSELGly4, displayed similar growth, substrate consumption, and product formation characteristics. The growth profile was very rapid and reached an exponential phase within $10 \mathrm{~h}$ of fermentation (Figure 2C for DUSELGly4). Once the fermentation reached a stationary phase at $66 \mathrm{~h}$, only about $10 \%$ of the initial glycerol concentration was consumed by these isolates leading to the formation of PDO (1.44-1.64 g/L) and ethanol $(1.18-1.27 \mathrm{~g} / \mathrm{L})$ as the major fermentation products. Due to the formation of acidic products (e.g., acetic and succinic acid), the $\mathrm{pH}$ of the fermentation broth decreased rapidly from 7.0 to 5.2 during exponential growth phase. Unlike acetic acid which appeared as a byproduct $(0.09 \mathrm{~g} / \mathrm{L})$ along with PDO and ethanol at the end of fermentation, the concentration of succinic acid dropped below the limit of detection at the end of batch fermentation (data not shown). Specific growth and metabolite product profiles suggested that PDO was a growth-associated product (concentration increased with increase in cell growthFigure 2C). HPLC analysis of fermentation broths also detected two peaks which were not identified and further investigations of these peaks are needed to ensure the identities of all end products that were formed during glycerol fermentation. These peaks may represent 2-3, butanediol, butanol, or butyric acid as previous studies have shown such intermediates in the oxidative and reductive pathways for the fermentation of glycerol in major PDO producers such as Clostridium, Klebsiella, Lactobacillus, and Citrobacter (Biebl, 1991; Maervoet et al., 2011; Rodriguez et al., 2012).

Molecular analysis based on $16 \mathrm{~S}$ rRNA sequence suggested that all glycerol-fermenting isolates were closely related to Clostridium sp. (Figure 1). Interestingly, bacterial strains belonging to genus Clostridium have been shown as the best "PDO producers" and extensively used in bio-based production of PDO because of their appreciable substrate tolerance, yield, and productivity (González-Pajuelo et al., 2006; Chatzifragkou et al., 2011; Wilkens et al., 2012). DUSELGly4 demonstrated a higher specific growth rate of $0.048 \mathrm{~h}^{-1}$, ethanol yield of $0.35 \mathrm{~g} / \mathrm{g}$, and PDO yield of $0.458 \mathrm{~g} / \mathrm{g}$ in comparison with other two glycerol-fermenting deep-mine strains (Figure 2C, Tables 1 and 2). The PDO yield of DUSELGly4 (0.458 g PDO/g of glycerol) was comparable to other reported species such as K. pneumoniae M5al $0.41 \mathrm{~g} / \mathrm{g}$ (Cheng et al., 2006) and 0.496 g/g C. butyricum (González-Pajuelo et al., 2004). Overall these results suggest that DUSELGly isolates 
Table 1 | Growth rates and yield coefficients of xylose-, glucose-, and glycerol-fermenting deep-mine isolates.

\begin{tabular}{|c|c|c|c|c|c|c|c|}
\hline Isolate & DUSELXyl3 & DUSELGlu1 & DUSELGlu2 & DUSELGlu4 & DUSELGly1 & DUSELGly3 & DUSELGly4 \\
\hline Specific growth rate $\mu\left(\mathrm{h}^{-1}\right)$ & 0.025 & 0.030 & 0.032 & 0.038 & 0.031 & 0.037 & 0.048 \\
\hline $\mathrm{pH}$ (initial - final) & $10.0-4.50$ & $10.0-4.76$ & $10.0-3.7$ & $10.0-4.65$ & $7.0-5.22$ & $7.0-5.32$ & $7.0-5.22$ \\
\hline
\end{tabular}

Calculations were done as described in "Materials and Methods" under "Determination of Specific Growth Rates and Yield Coefficients" section.

${ }^{a}$ Growth yield (YX/S) - $g$ of biomass produced per $g$ of substrate (Xylose, glucose, or glycerol) consumed.

Table 2 | Products and yield coefficients of xylose-, glucose-, or glycerol-fermenting deep-mine isolates.

\begin{tabular}{|c|c|c|c|c|c|}
\hline Isolate & $\begin{array}{l}\text { Substrate used } \\
\text { in fermentation }\end{array}$ & \multicolumn{2}{|c|}{ Fermentation end products } & \multicolumn{2}{|c|}{ Yield coefficients } \\
\hline DUSELGlu1 & Glucose & Ethanol & Acetic acid & 0.205 & NA \\
\hline DUSELGlu2 & Glucose & Ethanol & Acetic acid and Lactic acid & 0.304 & NA \\
\hline DUSELGlu4 & Glucose & Ethanol & Acetic acid & 0.293 & NA \\
\hline DUSELGly3 & Glycerol & PDO and Ethanol & Acetic acid and succinic acid & 0.298 & 0.367 \\
\hline DUSELGly4 & Glycerol & PDO and Ethanol & Acetic acid and succinic acid & 0.350 & 0.458 \\
\hline
\end{tabular}

Calculations were done as described in "Materials and Methods" under "Determination of Specific Growth Rates and Yield Coefficients" section.

${ }^{a}$ Ethanol yield $\left(Y_{E T / S}\right)$ - $g$ of ethanol formed per $g$ of substrate (xylose, glucose, or glycerol) consumed.

${ }^{b} P D O$ Yield $\left(Y_{P D / S}\right)$ - $g$ of PDO formed per $g$ of glycerol consumed.

NA—not applicable.

characterized in this study can ferment glycerol to $\mathrm{PDO}$ at $\mathrm{pH} 7$ with comparatively good yield.

\section{CONCLUSIONS}

The former Homestake gold mine represents a promising source for bioprospecting high-value microbes and microbial enzymes including those capable of degrading lignocellulosic biomass. Fermentation capabilities of glucose- and xylose-fermenting strains at alkaline $\mathrm{pH}$ have application in ethanol production from alkali-treated biomass. In an earlier study, we have shown that soil samples that were used to enrich and isolate glucose-, xylose-, and glycerol-fermenting strains contained high amounts of toxic metals such as $\mathrm{As}, \mathrm{Cd}, \mathrm{Cu}$, and $\mathrm{Pb}$ due to mining activities (Rastogi et al., 2009a,b). Although, we did not study glycerol fermentation in the presence of toxic metals, isolation of fermenting strains from soil with high levels of toxic metals indicates that these bacteria would be adapted to tolerate toxic heavy metals. These newly isolated deep-mine strains, if they have metal-tolerance, would be of particular biotechnological interest as heavy metals are generally present as impurities in crude glycerol (Johnson and Taconi, 2007). DUSEL strains also showed potential for the production of major industrial products including acetic acid (e.g., by DUSELXyl3) and PDO. The efficiency of these strains could be further improved by optimizing growth media composition and culture conditions. In addition, $\mathrm{pH}$-controlled batch experiments should be run to show the capabilities of ethanol production by these mine isolates at high $\mathrm{pHs}$. A better understanding of the inhibition effect of ethanol, PDO, and $\mathrm{pH}$ on growth rates of deep-mine isolates will be required to overcome any inhibitory effect that these might have on sugar fermentation.

Deep-mine strains will also be evaluated to test their ability to ferment all three carbon sources (xylose, glucose, and glycerol). Molecular characterization of deep-mine strains using techniques such as DNA-DNA hybridization or using other phylogenetic marker genes are also needed. Further elucidation of metabolic pathways leading to the formation of ethanol, acetic acid, or PDO will be desirable for the construction of recombinant strains for industrial applications.

\section{ACKNOWLEDGMENTS}

This research was funded by the Nelson Research Award funds and South Dakota Board of Regents Competitive Research Grant (Award No. SDBOR/SDSMT 2010-09-05). Aditya Bhalla and Rajesh Sani gratefully acknowledge the financial support provided by National Science Foundation - Industry/University Cooperative Research Center (NSF-I/UCRC, Grant \#441087). The support from the office of Vice President for Research and Department of Chemical and Biological Engineering at the South Dakota School of Mines and Technology is also acknowledged. Sudhir Kumar is thankful to Jaypee University of Information Technology, Solan, HP, India for granting a sabbatical leave for doing research work at the South Dakota School of Mines and Technology, SD, USA. 


\section{REFERENCES}

Alain, K., Pignet, P., Zbinden, M., Quillevere, M., Duchiron, F., Donval, J. P., et al. (2002). Caminicella sporogenes gen. nov., sp. nov., a novel thermophilic sporeforming bacterium isolated from an East-Pacific Rise hydrothermal vent. Int. J. Syst. Evol. Microbiol. 52, 1621-1628.

Balasubramanian, N., Kim, J. S., and Lee, Y. Y. (2001). Fermentation of xylose into acetic acid by Clostridium thermoaceticum. Appl. Biochem. Biotechnol. 93, 367-376.

Barbirato, F., Himmi, H. E., Conte, T., and Bories, A. (1998). 1, 3propanediol production by fermentation: an interesting way to valorize glycerin from the ester and ethanol industries. Ind. Crops Prod. 7, 281-289.

Biebl, H. (1991). Glycerol fermentation of 1,3-propanediol by Clostridium butyricum measurement of product inhibition by use of $\mathrm{pH}$-auxostat. Appl. Microbiol. Biotechnol. 35, 701-705.

Chatzifragkou, A., Papanikolaou, S., Dietz, D., Doulgeraki, A. I., Nychas, G. J., and Zeng, A. P. (2011). Production of 1, 3-propanediol by Clostridium butyricum growing on biodiesel-derived crude glycerol through a non-sterilized fermentation process. Appl. Microbiol. Biotechnol. 91, 101-112.

Cheng, K. K., Zhang, J. A., Liu, D. H., Sun, Y., Yang, M. D., and Xu, J. M. (2006). Production of 1,3propanediol by Klebsiella pneumoniae from glycerol broth. Biotechnol. Lett. 28, 1817-1821.

Chhatwal, I. (2008). Copper and Zinc Induced Growth Inhibition to Coeur d'Alene Microbial Isolates. Thesis, South Dakota School of Mines and Technology, Rapid City, SD, USA.

da Silva, G. P., Mack, M., and Contiero, J. (2009). Glycerol: a promising and abundant carbon source for industrial microbiology. Biotechnol. Adv. 27, 30-39.

de Carvalho Lima, K. G., Takahashi, C. M., and Alterthum, F. (2002). Ethanol production from corn cob hydrolysates by Escherichia coli KO11. J. Ind. Microbiol. Biotechnol. 29, 124-128.

Dharmadi, Y., and Gonzalez, R. (2005). A better global resolution function and a novel iterative stochastic search method for optimization of HPLC separation. J. Chromatogr. A 1070, 89-101.

Dien, B. S., Cotta, M. A., and Jeffries, T. W. (2003). Bacteria engineered for fuel ethanol production: current status. Appl. Microbiol. Biotechnol. 63, 258-266.

Eliasson, A., Christensson, C., Wahlbom, C. F., and HahnHägerdal, B. (2000). Anaerobic xylose fermentation by recombinant Saccharomyces cerevisiae carrying XYL1, XYL2, and XKS1 in mineral medium chemostat cultures. Appl. Environ. Microbiol. 66, 3381-3386.

Gonzalez-Hernandez, J. L., Sarath, G., Stein, J. M., Owens, V., Gedye, K., and Boe, A. (2009). A multiple species approach to biomass production from native herbaceous perennial feedstocks. In Vitro Cell. Dev. Biol. Plant 45, 267-281.

González-Pajuelo, M., Andrade, J. C., and Vasconcelos, I. (2004). Production of 1, 3-propanediol by Clostrdium butyricum VPI (3266). using a synthetic medium and raw glycerol. J. Ind. Microbiol. Biotechnol. 31, 442-446.

González-Pajuelo, M., MeynialSalles, I., Mendes, F., Soucaille, P., and Vasconcelos, I. (2006). Microbial conversion of glycerol to 1, 3-Propanediol: physiological comparison of a natural producer, Clostridium butyricum VPI 3266, and an engineered strain, C. acetobutylicum DG1(pSPD5). Appl. Environ. Microbiol. 72, 96-101.

Himmel, M. E., Ding, S. Y., Johnson, D. K., Adney, W. S., Nimlos, M. R., Brady, J. W., et al. (2007). Biomass recalcitrance: engineering plants and enzymes for biofuels production. Science 315, 804-807.

Jiang, L., Wang, J., Liang, S., Wang, X., Cen, P., and Xu, Z. (2010). Production of butyric acid from glucose and xylose with immobilized cells of Clostridium tyrobutyricum in a fibrous-bed. Appl. Biochem. Biotechnol. 160, 350-359.

Johnson, D. T., and Taconi, K. A. (2007). The glycerin glut: options for the value-added conversion of crude glycerol resulting from biodiesel production. Environ. Prog. 26, 338-348.

Karunanithy, C., and Muthukumarappan, K. (2011). Optimization of alkali soaking and extrusion pretreatment of prairie cord grass for maximum sugar recovery by enzymatic hydrolysis. Biochem. Eng. J. 54, 71-82.

Krishnan, M. S., Ho, N. W., and Tsao, G. T. (1999). Fermentation kinetics of ethanol production from glucose and xylose by recombinant Saccharomyces 1400(pLNH33). Appl. Biochem. Biotechnol. 77-79, 373-388.

Kumar, S., Tamura, K., and Nei, M. (1993). MEGA: Molecular
Evolutionary Genetics Analysis. University Park, TX: Pennsylvania State University.

Maervoet, V. E. T., De Mey, M., Beauprez, J., De Maeseneire, S., and Soetaert, W. K. (2011). Enhancing the microbial conversion of glycerol to 1,3-Propanediol using metabolic engineering. Org. Process Res. Dev. 15, 189-202.

Murarka, A., Dharmadi, Y., Yazdani, S. S., and Gonzalez, R. (2008) Fermentative utilization of glycerol by Escherichia coli and its implications for the production of fuels and chemicals. Appl. Environ. Microbiol. 74, 1124-1135.

Ni, Y., and Sun, Z. (2009). Recent progress on industrial fermentative production of acetone-butanol-ethanol by Clostridium acetobutylicum in China. Appl. Microbiol. Biotechnol. $83,415-423$.

Ou, M. S., Mohammed, N., Ingram, L. O., and Shanmugam, K. T (2009). Thermophilic Bacillus coagulans requires less cellulases for simultaneous saccharification and fermentation of cellulose to products than mesophilic microbial biocatalysts. Appl. Biochem. Biotechnol. 155, 379-385.

Rastogi, G., Bhalla, A., Adhikari, A., Bischoff, K. M., Hughes, S. R. Christopher, L. P., et al. (2010a), Characterization of thermostable cellulases produced by Bacillus and Geobacillus strains. Bioresour. Technol. 101, 8798-8806.

Rastogi, G., Osman, S., Kukkadapu, R., Engelhard, M., Vaishampayan, P. A., Andersen, G. L., et al. (2010b), Microbial and mineralogical characterizations of soils collected from the deep biosphere of the former Homestake gold mine, South Dakota. Microb. Ecol. 60, 539-550.

Rastogi, G., Muppidi, G. L., Gurram, R. N., Adhikari, A., Bischoff, K. M., Hughes, S. R., et al. (2009a) Isolation and characterization of cellulose-degrading bacteria from the deep subsurface of the Homestake gold mine, Lead, South Dakota, USA. J. Ind. Microbiol. Biotechnol. 36, 585-598.

Rastogi, G., Stetler, L. D., Peyton, B. M., and Sani, R. K. (2009b). Molecular analysis of prokaryotic diversity in the deep subsurface of the former Homestake gold mine, South Dakota, U. S. A. J. Microbiol. 47, 371-384.

Rodriguez, M. A. A., Gozzi, A., de Abreu Filho, B. A., Zanin, G. M., and de Moraes, F. F. (2012). Potential of Klebsiella oxytoca for 1, 3-propanediol production from glycerol under excess substrate conditions. Afr. J. Biotechnol. 11, 12675-12681.

Romero, S., Merino, E., Bolívar, F. Gosset, G., and Martinez, A. (2007). Metabolic engineering of Bacillus subtilis for ethanol production: lactate dehydrogenase plays a key role in fermentative metabolism. Appl. Environ. Microbiol. 73, 5190-5198.

Sani, R. K., Geesey, G. G., and Peyton, B. M. (2001). Assessment of lead toxicity to Desulfovibrio desulfuricans G20: influence of components of lactate C medium. Adv. Environ. Res. 5, 269-276.

Sani, R. K., Rastogi, G., Moberly, J. G., Dohnalkova, A., Ginn, T. R., Spycher, N., et al. (2010). The toxicity of lead to Desulfovibrio desulfuricans G20 in the presence of goethite and quartz. J. Basic Microbiol. 2, $160-170$.

Saxena, R. K., Anand, P., Saran, S., and Isar, J. (2009). Microbial production of 1, 3-propanediol: recent developments and emerging opportunities. Biotechnol. Adv. 27, 895-913.

Slobodkin, A. I., Tourova, T. P., Kostrikina, N. A., Chernyh, N. A., Bonch-Osmolovskaya, E. A., Jeanthon, C., et al. (2003). Tepidibacter thalassicus gen. nov., sp. nov., a novel moderately thermophilic, anaerobic, fermentative bacterium from a deep-sea hydrothermal vent. Int. J. Syst. Evol. Microbiol. 53, 1131-1134.

Slobodkina, G. B., Kolganova, T. V., Tourova, T. P., Kostrikina, N. A., Jeanthon, C., Bonch-Osmolovskaya, E. A., et al. (2008). Clostridium tepidiprofundi sp. nov., a moderately thermophilic bacterium from a deep-sea hydrothermal vent. Int. J. Syst. Evol. Microbiol. 58, 852-855.

Thompson, J., and He, B. B. (2006). Characterization of crude glycerol from biodiesel production from multiple feedstock. Appl. Eng. Agri. 22, 261-265.

Valdivieso, M. (2010, May 19). MicroBiOil: From Crude Glycerin to Biodiesel. Biodiesel Magazine.

Wilkens, E., Ringel, A. K., Hortig, D., Willke, T., and Vorlop, K. D. (2012). High-level production of 1 , 3-propanediol from crude glycerol by Clostridium butyricum AKR102a. Appl. Microbiol. Biotechnol. 93, 1057-1063.

Willke, T., and Vorlop, K. (2008). Biotransformation of glycerol into 1, 3-propanediol. Eur. J. Lipid Sci. Technol. 110, 831-840.

Yazdani, S. S., and González, R. (2007). Anaerobic fermentation of glycerol: a path to economic viability for 
the biofuels industry. Curr. Opin. Biotechnol. 18, 213-219.

Yazdani, S. S., Mattam, A. J., and Gonzalez, R. (2010). "Fuel and chemical production from glycerol, a biodiesel waste product," in Biofuels from Agricultural Wastes and Byproducts, eds H. Blaschek, T. Ezeji, and J. Scheffran (Ames, IA: Blackwell Publishing), 97-116.

Yomano, L. P., York, S. W., and Ingram, L. O. (1998). Isolation and characterization of ethanol-tolerant mutants of Escherichia coli KO11 for fuel ethanol production. J. Ind. Microbiol. Biotechnol. 20, 132-138.

Zaldivar, J., Nielsen, J., and Olsson, L. (2001). Fuel ethanol production from lignocellulose: a challenge for metabolic engineering and process intergration. Appl. Microbiol. Biotechnol. 56, 17-34.

Zhao, Y. N., Chen, G., and Yao, S. J. (2006). Microbial production of 1, 3-propanediol from glycerol by encapsulated Klebsiella pneumoniae. Biochem. Eng. J. 32, 93-99.

Zheng, Y., Pan, Z., and Zhang, R. (2009). Overview of biomass pretreatment for cellulosic ethanol production. Int. J. Agric. Biol. Eng. 2, 51-68.

Zheng, Z. M., Cheng, K. K., Hu, Q. L., Liu, H. J., Guo, N. N., and Liu, D. H. (2008). Effect of culture conditions on 3-hydroxypropionaldehyde detoxification in 1, 3-propanediol fermentation by Klebsiella pneumonia. Biochem. Eng. J. 39, 305-310.

Conflict of Interest Statement: The authors declare that the research was conducted in the absence of any commercial or financial relationships that could be construed as a potential conflict of interest.

Received: 22 November 2012; paper pending published: 12 December 2012; accepted: 27 January 2013; published online: 15 February 2013.

Citation: Rastogi G, Gurram RN, Bhalla A, Gonzalez R, Bischoff KM, Hughes SR, Kumar S and Sani RK (2013) Presence of glucose, xylose, and glycerol fermenting bacteria in the deep biosphere of the former Homestake gold mine, South Dakota. Front. Microbio. 4:18. doi: 10.3389/fmicb.2013.00018

This article was submitted to Frontiers in Microbiotechnology, Ecotoxicology and Bioremediation, a specialty of Frontiers in Microbiology.

Copyright () 2013 Rastogi, Gurram, Bhalla, Gonzalez, Bischoff, Hughes, Kumar and Sani. This is an open-access article distributed under the terms of the Creative Commons Attribution License, which permits use, distribution and reproduction in other forums, provided the original authors and source are credited and subject to any copyright notices concerning any third-party graphics etc. 